\title{
Amantadine and levodopa in the treatment of Parkinson's disease
}

\begin{abstract}
Twenty-eight ambulatory patients with Parkinson's disease participated in successive double-blind crossover trials of amantadine and levodopa. A comprehensive battery of tests was used to evaluate patient preference, neurologic symptoms and signs, quantitative neurologic performance, practical skills used in daily living, and neuropsychological performance. These permitted differential assessment of specific areas of function affected.

Levodopa ameliorated functional disabilities, tremor, and loss of associated movements. It also improved grip strength, foot speed, foot coordination, gait, and several skilled activities more than did amantadine. The combination of levodopa and amantadine was more effective than levodopa alone in the management of total functional disability, tremor, and gait and in tests of grip strength, finger coordination, tracking, and tandem gait, as well as in the practiced skills of zipping, cutting, and opening a door. One neuropsychologic test-picture completion-was also better on the combination. The safety of the combination was affirmed and the relative efficacy quantitated.
\end{abstract}

\author{
Jonathan E. Walker, M.D., Alfred Potvin, Ph.D., Wallace Tourtellotte, M.D., Ph.D., \\ James Albers, Ph.D., Brian Repa, M.S., William Henderson, Ph.D., and \\ Dorothy Snyder, B.S. Ann Arbor, Mich. \\ The Departments of Neurology and Bioengineering, The University of Michigan
}

In a previous study, we ${ }^{10}$ addressed ourselves to the question of whether amantadine was effective in the treatment of Parkinson's disease. By qualitative and quantitative criteria, amantadine (Symmetrel) was found to be a safe and effective agent, with specific improvement occurring in tests involving gait, coordina-

Supported by the E. I. DuPont de Nemours \& Co., Inc., the K. H. Campbell Foundation, and an equipment grant from the University of Michigan Institute of Science and Technology.

Received for publication Sept. 24, 1971.

Accepted for publication Oct. 25, 1971.

Reprint requests to: Dr. Walker, Division of Neurology. University of Colorado Medical Center, Denver Colo. 80220 . tion, strength, and more complex activities of daily living. We here report a comparison of levodopa, amantadine, and the combination of the two in the therapy of parkinsonism, using the same battery of subjective and objective tests of neurologic and neuropsychological function as in the previous study ${ }^{10}$ and incorporating an additional battery of tracking tests designed to measure more complex coordinated movements.

\section{Patients and methods}

Twenty-eight of the 42 patients participating in the previous trial remained for the 18 month duration of the experiment. 
The original selection method, the tests used, and the principles of test application have been described. ${ }^{10} \mathrm{~A}$ section of the results deals with those patients who did not complete the trial for one reason or another. At the conclusion of the previous trial, each patient was begun on levodopa therapy and amantadine was gradually withdrawn. The dose of levodopa was gradually increased over the following 4 to 5 months, until the patient reached a stable, maximal tolerable dose; that is, the dose was increased by 250 to $500 \mathrm{mg}$. increments once or twice weekly until each patient developed nausea or other troublesome side effects. When such an effect was encountered, the patient was given the immediately preceding dose, and we waited one week before attempting to increase the dose. The patient was considered to have reached his maintenance dose only after 3 or more unsuccessful attempts were made to exceed the dose which produced the troublesome side effect. The only side effects we considered acceptable were mild nausea and anorexia without weight loss. Each patient had been on levodopa therapy for at least 6 months and had been on maintenance dosage for at least 6 weeks at the time of the first test period. After evaluation on levodopa alone, patients were randomly allocated into two treatment groups, with the use of a double-blind design. One group was given $100 \mathrm{mg}$. of amantadine twice daily and the other a placebo capsule of identical taste and appearance twice daily. Three weeks later, patients returned for evaluation. An interval history was obtained and neurologic function evaluated. The amantadine and placebo groups were then crossed over. Three weeks later, the patients returned for a final evaluation. Each patient had been evaluated by history and test battery 7 times by the completion of the trial, but only the last 5 evaluations are analyzed in this report.

Evaluations were made: ( 1 ) on placebo alone, (2) on amantadine alone, (3) on levodopa alone, (4) on levodopa plus placebo, and (5) on levodopa plus
Table I. Side effects limiting dosage of levodopa

\begin{tabular}{l|c|c}
\hline \multicolumn{1}{c|}{ Side effect } & $\begin{array}{c}\text { No. of } \\
\text { patients }\end{array}$ & $\begin{array}{c}\text { Average dose } \\
\text { (Gm./day) }\end{array}$ \\
\hline $\begin{array}{l}\text { Nausea with vomiting } \\
\text { Anorexia and weight }\end{array}$ & 12 & 4.3 \\
$\quad$ loss & 4 & 3.4 \\
$\begin{array}{l}\text { Dyskinesias (limb, face, } \\
\text { or axial) }\end{array}$ & 4 & 2.1 \\
$\begin{array}{l}\text { Depression } \\
\text { Increased rigidity and }\end{array}$ & 2 & 3.0 \\
$\quad$ akinesia \\
$\begin{array}{l}\text { Nervousness, itchy } \\
\text { hands }\end{array}$ \\
$\begin{array}{l}\text { Bitter taste, burning } \\
\text { tongue }\end{array}$ & 1 & 4.5 \\
$\begin{array}{l}\text { Confusion and paranoia } \\
\text { Orthostatic hypotension }\end{array}$ & 1 & 5.0 \\
$\begin{array}{l}\text { Anarthria, dysphagia, } \\
\text { freezing }\end{array}$ & 1 & 3.0 \\
\hline
\end{tabular}

amantadine. Crossovers occurred between Examinations 1 and 2 (placebo versus amantadine) and between Examinations 4 and 5 (levodopa plus placebo versus levodopa plus amantadine). Age-matched control subjects in good health (predominantly the husbands and wives of the patients) were used to establish normal values. ${ }^{7}$ The patient group consisted of 12 women and 16 men, with an average age of 65.6 years, average disease duration of 9.25 years, and average stage of 2.9 , according to the classification of Hoehn and Yahr. ${ }^{3}$ The average maintenance dose of levodopa was $3.58 \mathrm{Gm}$. per day (50 mg. per kilogram per day) and, as noted, they had been on this maximal tolerable maintenance dose for at least 6 weeks when first tested for the levodopa effect.

\section{Results}

Dose-limiting side effects for levodopa treatment. Table I lists side effects and doses of levodopa in our 28 patients. Dyskinetic and affective complications tended to appear at a lower dose than did the 
Table II. Disability, pulse, and blood pressure

\begin{tabular}{lcccccc}
\hline \multicolumn{1}{c|}{ Parameter } & Placebo & Amantadine & Levodopa & $\begin{array}{c}\text { Levodopa }+ \\
\text { placebo }\end{array}$ & $\begin{array}{c}\text { Levodopa }+ \\
\text { amantadine }\end{array}$ \\
\hline Walking & 2.6 & $2.0^{*}$ & 1.8 & 1.9 & 1.7 \\
Dressing & 2.9 & 2.6 & $2.4 \uparrow$ & 2.5 & 2.3 \\
Hygiene & 3.3 & $3.1 \uparrow$ & $2.5^{*}$ & 2.8 & 2.7 \\
Eating & 1.1 & $0.90 \uparrow$ & 0.81 & 0.88 & 0.81 \\
Feeding & 2.1 & 1.9 & 1.6 & 1.5 & 1.4 \\
Speech & 2.8 & $2.3^{*}$ & 2.1 & 1.9 & 1.7 \\
Pulse & 80.9 & 79.4 & 81.8 & 83.0 & 83.9 \\
Blood pressure & & & & & \\
$\quad$ Systolic & 121.1 & 122.3 & 125.2 & 125.4 & 125.2 \\
Diastolic & 79.8 & 78.0 & 79.8 & 80.2 & 79.9 \\
\hline
\end{tabular}

p $<0.01$.

tp $<0.05$.

other side effects. Only nausea with actual vomiting or significant weight loss was considered sufficient reason for not increasing the dose. The maximal tolerable dose for the women ( $45.4 \mathrm{mg}$. per kilogram per day) was considerably lower on the average than that for the men ( $54.3 \mathrm{mg}$. per kilogram per day). All the side effects of levodopa encountered disappeared with reduction in dosage.

Comparisons of treatment groups (Tables II to VI). In the second column of each table, tests which were significantly improved with amantadine are indicated by asterisks. In Tables IV to VI, the values are expressed in terms of percentage of normal function. Because of the large number of tests involved in the quantitative evaluation of neurologic function (QENF), only those tests which were significantly changed at some time during the trial have been listed. The third column of each table indicates comparisons of amantadine and levodopa. In the last two columns, levodopa plus amantadine and levodopa plus placebo are compared.

Amantadine. The results in the $29 \mathrm{pa-}$ tients who completed the entire trial are in agreement with the analysis of all 42 patients previously reported. ${ }^{10}$ Seven of 27 neurologic signs, 4 of 6 disability categories,
15 of 42 quantitative tests of neurologic function, and 9 of 19 simulated activities of daily living were significantly better on amantadine than on placebo. The only psychological test which improved was the digit symbol substitution test, which involves fine motor coordination. Because of the extensive analysis in the previous paper, this comparison will not be described further here, but it clearly indicates superiority of amantadine over placebo.

Levodopa versus amantadine. The patients reported greater improvement on levodopa than amantadine in functional disability in 4 of the 6 categories evaluated -dressing, hygiene, feeding, and speech. The neurologists judged a significant overall improvement of tremor in the upper extremities, finger movements of the dominant hand, and associated bodily movements bilaterally. For all the other symptoms and signs evaluated, the two drugs produced indistinguishable benefits.

The quantitative tests revealed a more striking superiority of levodopa over amantadine. Twelve of 42 QENF tests showed greater improvement on levodopa, including grip strength, foot speed, foot coordination, and tandem gait. There was also a slight but significant improvement in two-point discrimination. Amantadine 
Table III. Standard neurologic examination

\begin{tabular}{|c|c|c|c|c|c|}
\hline Test & Placebo & Amantadine & Levodopa & $\begin{array}{c}\text { Levodopa }+ \\
\text { placebo }\end{array}$ & $\begin{array}{l}\text { Levodopa }+ \\
\text { amantadine }\end{array}$ \\
\hline \multicolumn{6}{|l|}{ Tremor } \\
\hline Right hand & 3.4 & $2.9^{*}$ & $2.5^{*}$ & 2.1 & $1.8^{*}$ \\
\hline Left hand & 2.1 & 1.8 & $1.5^{*}$ & 1.4 & 1.1 \\
\hline Right leg & 1.1 & 0.9 & 0.8 & 0.8 & $0.5^{\text {* }}$ \\
\hline Left leg & 0.8 & 0.7 & 0.5 & 0.5 & $0.2^{*}$ \\
\hline Rigidity, left arm & 1.4 & $0.9^{*}$ & 0.7 & 0.7 & 0.6 \\
\hline \multicolumn{6}{|l|}{ Finger coordination } \\
\hline Right & 2.7 & 2.4 & $1.9^{*}$ & 1.8 & 1.7 \\
\hline Left & 2.5 & $2.0 \nmid$ & 1.6 & 1.6 & 1.5 \\
\hline Bradykinesia & 2.3 & $1.9 \nmid$ & 1.6 & 1.5 & 1.4 \\
\hline Weakness, right leg & 1.0 & $0.5^{*}$ & 0.4 & 0.4 & 0.4 \\
\hline Rising & 1.6 & $1.1^{*}$ & 1.0 & 1.0 & 1.0 \\
\hline Posture & 2.5 & 2.0 & 1.8 & 1.8 & 1.6 \\
\hline Gait & 2.0 & $1.6^{*}$ & 1.5 & 1.5 & $1.3^{*}$ \\
\hline \multicolumn{6}{|c|}{ Loss of associative movement } \\
\hline Right & 4.2 & 4.1 & $3.6^{*}$ & 3.6 & 3.4 \\
\hline Left & 3.8 & 3.6 & $3.1 \ddagger$ & 3.1 & 2.9 \\
\hline
\end{tabular}

Only those tests showing significant change at some time during the trial are listed.

${ }^{\circ} \mathrm{p}<0.05$.

$+\mathrm{p}<0.01$.

tp $<0.001$.

and levodopa produced indistinguishable improvement in hand coordination, rotary pursuit, and pencil flipping. Analysis of the more complex and skilled activities of daily living (SADL) revealed that in 5 of 19 there was significantly better performance on levodopa than on amantadine (use of zipper, cutting utensils, fork, safety pin, opening an envelope). The two drugs produced indistinguishable improvement in use of a small button, tying a bow, squeezing toothpaste, dialing a telephone, drinking from a glass, and scrubbing the hands. If the SADL tests are all combined, levodopa produces an average 23.9 per cent improvement over placebo compared to a 6.4 per cent improvement for amantadine. The improvement in these complex practiced skills is more striking than for the more basic abilities tested by the QENF. Of the nine neuropsychologic tests, two showed significantly better performance on levodopa (digit symbol substitution and object assembly) than amantadine. Both have a motor output.

Neither drug produced significant improvement in cogwheeling, speed of rapid alternating movements, speed of foot tapping, leg rigidity, or postural stability with the eyes closed. A slight but significant decrease in grip strength was noted after amantadine, while a similar decrease in deltoid strength was noted after levodopa.

Levodopa plus amantadine. No individual category of functional disability was significantly better on the combination of drugs, but all the scores were lower on the average. If all the disability scores are summed, the combination of levodopa and amantadine was significantly better than levodopa alone.

Scores from the standard neurologic examination reveal that the combination improves arm tremor, leg tremor, and gait more than does levodopa alone. Analysis of the QENF tests reveals that the combi- 
Table IV. Quantitative evaluation of neurologic function

\begin{tabular}{|c|c|c|c|c|c|}
\hline \multirow[b]{2}{*}{ Test } & \multicolumn{5}{|c|}{ Per cent of normal function } \\
\hline & Placebo & Amantadine & Levodopa & $\begin{array}{l}\text { Levodopa }+ \\
\quad \text { placebo }\end{array}$ & $\begin{array}{l}\text { Levodopa }+ \\
\text { amantadine }\end{array}$ \\
\hline \multicolumn{6}{|l|}{ Grip strength } \\
\hline $\mathrm{D}$ & 60.3 & $67.7^{*}$ & $74.2^{*}$ & 68.3 & $73.6 \nmid$ \\
\hline $\mathrm{N}$ & 58.2 & $64.3+$ & $70.3 \uparrow$ & 64.0 & 67.4 \\
\hline \multicolumn{6}{|l|}{ Shoulder strength } \\
\hline $\mathrm{D}$ & 68.4 & 74.7 & $65.8 \uparrow$ & 62.3 & 65.3 \\
\hline $\mathrm{N}$ & 67.6 & 69.4 & $60.0^{*}$ & 58.9 & 61.7 \\
\hline \multicolumn{6}{|l|}{ Hand coordination } \\
\hline D & 64.3 & $74.6^{*}$ & 73.3 & 73.1 & 71.5 \\
\hline $\mathrm{N}$ & 63.6 & $74.3^{*}$ & 71.6 & 71.2 & 74.9 \\
\hline \multicolumn{6}{|l|}{ Index of performance } \\
\hline $\mathrm{D}$ & 60.1 & $67.3^{*}$ & 66.1 & 68.6 & 68.9 \\
\hline $\mathrm{N}$ & 60.7 & $67.7^{*}$ & 66.3 & 65.4 & 69.4 \\
\hline Rotary pursuit (N) & 49.6 & $64.7^{*}$ & 69.9 & 75.1 & 87.9 \\
\hline \multicolumn{6}{|l|}{ Purdue pegboard } \\
\hline D & 46.8 & $53.9^{*}$ & $62.7^{*}$ & 62.0 & 65.0 \\
\hline $\mathbf{N}$ & 53.5 & $57.0 \nmid$ & $64.1^{*}$ & 66.6 & 69.8 \\
\hline \multicolumn{6}{|l|}{ Pencil flip } \\
\hline $\mathrm{D}$ & 41.6 & $45.1 \uparrow$ & 45.8 & 46.4 & 54.7 \\
\hline $\mathrm{N}$ & 46.7 & $50.7 \uparrow$ & 53.6 & 50.8 & 57.4 \\
\hline \multicolumn{6}{|c|}{ Two-point discrimination } \\
\hline $\mathrm{D}$ & 82.6 & 84.0 & $93.1^{*}$ & 92.1 & 92.6 \\
\hline $\mathrm{N}$ & 87.5 & 86.1 & $97.7 \$$ & 98.7 & $93.0 f$ \\
\hline \multicolumn{6}{|l|}{ Foot speed } \\
\hline $\mathrm{D}$ & 58.1 & 64.0 & $75.0 \nmid$ & 72.6 & 74.6 \\
\hline $\mathrm{N}$ & 56.3 & 57.6 & $70.6^{*}$ & 67.9 & $73.1 \uparrow$ \\
\hline \multicolumn{6}{|l|}{$\begin{array}{l}\text { Foot coordination } \\
\text { forward }\end{array}$} \\
\hline $\mathrm{D}$ & 46.6 & $54.3 \nmid$ & 60.5 & 59.3 & $66.6 \nmid$ \\
\hline $\mathrm{N}$ & 49.5 & $58.6 \uparrow$ & 64.5 & 63.7 & 70.3 \\
\hline \multicolumn{6}{|c|}{$\begin{array}{l}\text { Index of performance } \\
\text { forward }\end{array}$} \\
\hline $\mathrm{D}$ & 44.5 & 49.4 & $57.1 \uparrow$ & 56.2 & $63.5 \nmid$ \\
\hline $\mathrm{N}$ & 48.7 & 52.5 & $62.0^{*}$ & 59.0 & 64.4 \\
\hline \multicolumn{6}{|c|}{ Foot coordination side } \\
\hline $\mathrm{D}$ & 48.3 & $57.3 \nmid$ & 64.7 & 62.3 & $70.6 \uparrow$ \\
\hline $\mathrm{N}$ & 54.4 & $62.3 \uparrow$ & 72.1 & 69.2 & 71.9 \\
\hline \multicolumn{6}{|c|}{$\begin{array}{l}\text { Index of performance } \\
\text { side }\end{array}$} \\
\hline $\mathrm{D}$ & 42.4 & 50.4 & $59.5 \nmid$ & 57.2 & $61.8^{*}$ \\
\hline $\mathrm{N}$ & 47.5 & 53.4 & $61.9 \dagger$ & 61.0 & $66.0^{*}$ \\
\hline
\end{tabular}

Only those tests showing a significant change at some time during the trial are listed. $\mathrm{D}=$ dominant; $\mathrm{N}=$ nondominant.

${ }^{*} \mathrm{p}<0.01$.

tp $<0.05$.

$\neq \mathrm{p}<0.001$. 
Table IV. Cont'd

\begin{tabular}{l|c|c|c|c|c}
\hline & \multicolumn{5}{c}{ Per cent of normal function } \\
\cline { 2 - 6 } \multicolumn{1}{c|}{ Test } & Placebo & Amantadine & Levodopa & $\begin{array}{c}\text { Levodopa }+ \\
\text { placebo }\end{array}$ & $\begin{array}{c}\text { Levodopa }+ \\
\text { amantadine }\end{array}$ \\
\hline Tandem gait & & & & & \\
$\quad$ Supported & 53.2 & 58.3 & $67.6^{*}$ & 66.3 & $73.5^{*}$ \\
$\quad$ Unsupported & 48.9 & 51.9 & $63.1 \ddagger$ & 63.3 & 66.9 \\
Foot speed forward (N) & 80.1 & 78.6 & $83.3 \dagger$ & 78.4 & 82.2 \\
Touch toe (D) & 79.2 & 85.2 & $92.1 \dagger$ & 86.4 & 97.9 \\
Rest tremor (D) & - & - & 46.1 & 40.3 & $52.5 \dagger$ \\
Critical task score & - & - & - & 78.0 & $81.5 \dagger$ \\
$\begin{array}{l}\text { Movement time-left to } \\
\text { right }\end{array}$ & - & - & - & 83.4 & $86.0 \dagger$ \\
\hline
\end{tabular}

Table V. Simulated activities of daily living

\begin{tabular}{|c|c|c|c|c|c|}
\hline \multirow[b]{2}{*}{ Task } & \multicolumn{5}{|c|}{ Per cent of normal function } \\
\hline & Placebo & Amantadine & Levodopa & $\begin{array}{c}\text { Levodopa }+ \\
\text { placebo }\end{array}$ & $\begin{array}{l}\text { Levodopa }+ \\
\text { amantadine }\end{array}$ \\
\hline Shirt & 29.4 & $37.9^{*}$ & 47.4 & 52.5 & 56.1 \\
\hline \multicolumn{6}{|l|}{ Button } \\
\hline Large & 46.1 & 52.2 & 64.0 & 63.8 & 67.4 \\
\hline Small & 42.3 & $47.0 \dagger$ & 58.3 & 52.2 & 60.1 \\
\hline Zipper & 48.8 & $59.4 \dagger$ & $83.3 \uparrow$ & 81.7 & $88.6 \nmid$ \\
\hline Bow & 44.1 & $50.1 \uparrow$ & 69.5 & 56.5 & $64.2 \ddagger$ \\
\hline Cutting & 45.1 & $48.8 \dagger$ & $69.2 \ddagger$ & 63.2 & 73.3 \\
\hline Fork & 58.2 & 64.4 & $89.5 \ddagger$ & 91.4 & 95.9 \\
\hline Toothpaste & 52.0 & $59.2 \nmid$ & 75.3 & 82.7 & 78.7 \\
\hline Dialing & 68.1 & $74.2 \nmid$ & 83.2 & 80.7 & 77.9 \\
\hline Safety pin & 58.2 & 63.4 & $84.6+$ & 75.6 & 77.4 \\
\hline Envelope & 51.5 & 54.3 & $96.0 \dagger$ & 87.0 & 89.2 \\
\hline Door & 56.1 & 65.9 & 86.0 & 88.6 & $97.7 \nmid$ \\
\hline Drinking & 77.2 & $82.7 \dagger$ & 95.2 & 97.3 & 106.0 \\
\hline Vocalizing & 87.7 & 92.2 & 87.7 & 83.6 & 81.4 \\
\hline \multicolumn{6}{|l|}{ Scrub } \\
\hline D & 60.2 & $70.9 \ddagger$ & 89.5 & 87.4 & 94.3 \\
\hline $\mathrm{N}$ & 60.8 & $67.9 \neq$ & 81.1 & 73.5 & 81.2 \\
\hline \multicolumn{6}{|l|}{ Glove } \\
\hline $\mathrm{D}$ & 50.5 & 64.4 & 83.1 & 80.0 & 87.3 \\
\hline $\mathbf{N}$ & 57.5 & 59.8 & 85.8 & 82.7 & 91.4 \\
\hline Average & 55.5 & 61.9 & 79.4 & 76.7 & 81.6 \\
\hline
\end{tabular}

$\mathrm{D}=$ dominant; $\mathbf{N}=$ nondominant.

${ }^{\circ} \mathrm{p}<0.001$.

tp $<0.05$.

tp $<0.01$ 
Table VI. Neuropsychological tests

\begin{tabular}{l|c|c|c|c|c}
\hline & \multicolumn{5}{c}{ Per cent of normal function } \\
\cline { 2 - 6 } \multicolumn{1}{c|}{ Test } & & & & $\begin{array}{c}\text { Levodopa }+ \\
\text { placebo }\end{array}$ & $\begin{array}{c}\text { Levodopa }+ \\
\text { amantadine }\end{array}$ \\
\hline Similarities & Placebo & Amantadine & Levodopa & 87.5 & 90.9 \\
Digits & - & - & 83.0 & 96.1 & 100.0 \\
Written & 92.6 & 94.4 & 95.3 & 64.0 & 61.9 \\
Oral & 50.7 & 53.5 & 57.7 & 69.8 & 67.9 \\
Digit symbol & 68.4 & 65.5 & 64.6 & 60.5 & 63.4 \\
Object association & 49.6 & 55.0 & $61.5+$ & 88.7 & 93.5 \\
Picture arrangement & 84.6 & 78.5 & $82.0^{*}$ & 91.7 & 92.9 \\
Picture composition & 83.3 & 82.1 & 87.6 & 92.8 & $96.8^{*}$ \\
Verbal organization test & 84.4 & 87.6 & 86.4 & 95.6 & 97.5 \\
Raven IQ & 88.1 & 88.8 & 92.5 & 94.7 & 94.8 \\
Raven & 90.4 & 91.5 & 91.0 & 94.4 & 96.6 \\
\hline
\end{tabular}

" $p<0.05$.

tp $<0.01$.

nation is superior to levodopa alone for the following: dominant hand-grip strength, pencil flipping, dominant foot-foot coordination and index of performance, nondominant foot-foot speed, foot coordination and index of performance, and tandem gait, supported. Thus, amantadine seems to offer an additional boost in function, especially in terms of coordination in the hands and feet. This was also evident in the timed SADL tests, in which the combination was superior to levodopa alone for zipping, cutting, and opening a door. It is important to note that amantadine produced an incremental improvement averaging 4.9 per cent in these tests, even after the striking improvement by levodopa.

There was little further effect on neuropsychological performance with the addition of amantadine, only picture completion being significantly better. However, as the trial progressed, gradual improvement was noted in several other tests, although this was not statistically significant. When the combination of levodopa and amantadine was compared to initial placebo scores, significant improvement was noted for the written symbol digit, digit symbol, object assembly, picture completion, the verbal organization test, and the Raven progressive matrices.

Side effects of amantadine with levodopa. No new side effects were reported. ${ }^{10}$
One patient had recurrence of ankle edema which he had experienced when on amantadine in the earlier phase of the trial, and two women noted the return of livedo reticularis when amantadine was restarted.

Deaths. Two deaths occurred during the trial. The first patient developed symptoms of congestive heart failure during the first placebo period and this gradually worsened during amantadine and levodopa administration. Heart failure responded poorly to digitalis, diuretics, and the withdrawal of all anti-Parkinson medications, and she eventually died. The second patient had an unreported history of periodic ankle swelling and had previously taken digitalis and diuretics, though he was not taking them on admission to the study. Ankle swelling recurred both times when amantadine was given, and following the completion of the trial he developed orthopnea and paroxysmal nocturnal dyspnea. Amantadine was withdrawn and he seemed to be improving on digoxin and hydrochlorothiazide, when he developed acute urinary retention and suddenly died at home. Pulmonary embolism was suspected, but an autopsy was not permitted. Increased ambulation with consequent increased strain on the heart may have played a role in the precipitation of heart failure in this patient, though the relation of heart failure to amantadine was not clear in the 
first patient. Congestive heart failure may constitute a relative contraindication to amantadine administration.

\section{Discussion}

Our results indicate a somewhat different spectrum of effects of levodopa and amantadine in Parkinson's disease and indicate an additive effect when the two are combined. The use of a comprehensive, qualitative and quantitative test battery such as ours makes it possible to analyze such effects, as well as to screen for adverse effects on neurologic function.

Earlier trials, 1, 2, 4, 6, 8, 9 have yielded conflicting results concerning additional benefit from amantadine in patients already taking levodopa. Initial reports suggested that amantadine had an additive effect, but these were criticized on the basis of technique. ${ }^{4}$ Godwin-Austen and associates ${ }^{2}$ found no additional effect of amantadine in 12 patients who were taking levodopa and anticholinergic drugs on a stable regimen, but objective tests were not used in the evaluation. Hunter and associates ${ }^{4}$ used only a short "run-in" period of 17 to 24 days on levodopa before adding amantadine. Though additional improvement was noted, they attributed it to accumulated levodopa effect. Millac and associates, ${ }^{5}$ using an ordinal scoring system and a single timed test (walking a measured distance), found no incremental effect of amantadine. Parkes and associates $^{6}$ treated 66 patients for one year, 26 with amantadine alone and 40 more severely disabled patients with the combination of amantadine and levodopa. They found a rapid and persistent effect of amantadine, and recommend its use in milder cases of parkinsonism, because of the lower incidence and severity of side effects. None of the previous trials used a double-blind placebo controlled crossover program in studying the effects of amantadine in patients on a stable dose of levodopa. Our use of a large battery of tests makes possible the distinction of specific areas of function which improve, deteriorate, or are unchanged. Use of a total score, based or ordinal grading, may blur or distort these distinctions, masking important changes in specific functional categories.

\section{Conclusions}

1. Levodopa has been shown to be superior to amantadine in the relief of functional disability (dressing, hygiene, feeding, speech) and improving neurologic signs (hand tremor, finger coordination, and associated movements) of Parkinson's disease. Quantitative neurologic testing showed levodopa superior to amantadine in grip strength, foot speed, foot coordination, and tandem gait. The simulated activities of daily living which were improved more by levodopa than amantadine included buttoning a small button, tying a bow, squeezing toothpaste, dialing a telephone, drinking from a glass, and scrubbing the hands. Greater improvement was also noted in two psychomotor tasks.

2. The combination of levodopa and amantadine was better than levodopa alone in the relief of the following: qualitative tests-total functional disability, tremor of arms and legs, gait; quantitative tests-grip strength and pencil flipping in the dominant hand, foot speed and foot coordination, tandem gait; activities of daily living tests-zipping, cutting, opening a door; and neuropsychological tests-picture completion.

3. The safety and efficacy of the combination of the two drugs have again been demonstrated.

\section{References}

1. Fieschi, C., Nardini, M., Casacchia, M., Tedone, M. E., Reitano, M., and Robotti, E.: Amantadine versus $\mathrm{L}$-dopa and amantadine plus L-dopa, Lancet 2:154-155, 1970.

2. Godwin-Austen, R. B., Frears, C. C., Bergmann, S., Parkes, J. D., and Knill-Jones, R. P.: Combined treatment of parkinsonism with $\mathrm{L}$ dopa and amantadine, Lancet 2:383-385, 1970.

3. Hoehn, M. M., and Yahr, M. D.: Parkinsonism: Onset, progression and mortality, Neurology $17: 427-442,1967$.

4. Hunter, K. R., Stern. G. M., Laurence, D. R., 
and Armitage, P.: Combined treatment of parkinsonism with L-dopa and amantadine, Lancet 2:566, 1970.

5. Millac, P., Hasan, I., Espir, M. L. E., and Slyfield, D. G.: Treatment of parkinsonism with L-dopa and amantadine, Lancet 2:720, 1970.

6. Parkes, J. D., Curzon, G., Knott, P. J., et al.: Treatment of Parkinson's disease with amantadine and L-dopa, Lancet 1:1083-1086, 1971.

7. Potvin, A. R.: The effects of age, motivation, and learning on performance in the quantitative examination of neurological function, Ph.D. Thesis, University of Michigan, 1971.
8. Scotti, G.: Combined treatment of Parkinson's disease with amantadine and I-dopa, Lancet $1: 1395,1970$.

9. Voller, G. M.: Treatment of Parkinson's disease with amantadine, Dtsch. Med. Wochenschr. 95:934-937, 1970.

10. Walker, J. E., Albers, J. W., Tourtellotte, W. W., Henderson, W. G., Potvin, A. R., and Smith, A.: A qualitative and quantitative evaluation of amantadine in the treatment of Parkinson's disease, J. Chron. Dis. In press. 